сепаратным применением и дает возможность повысить эффективность лечения у больных с воспалительными заболеваниями переднего и заднего отрезка глазного яблока на 34,6\%.

Предложенный метод комплексного лечения больных увеитами туберкулезной этиологии прост в выполнении, хорошо переносится больными и может быть рекомендован для использования в широкой офтальмологической практике.

\section{ЛИТЕРАТУРА}

1. Асмолов О. К., Бабуріна О. А., Смолська І. М., Герасимова Н. А. Епідеміологічна ситуація з туберкульозу серед медичних працівників України та Одеської Області // Одеський медичний журнал. - 2 (88). 2005. - С.105-106.

2. Вопросы и ответы о стратегии DOTS // BO3. Женева. - 1998.

3. Крыжановская Т. И. // Тези науково-практ. конф. 3 міжнародною участю, присвячений 130-річчю 3 дня народження акад. В. П. Філатова. - Одеса, 2005. C.264-265.

4. Морозов В. И., Яковлев А. А. // Фармакотерапия глазных болезней. - М.: Медицина. - 2004. C. 244-246.

5. Офтальмологічна допомога в Україні за 2001-2005 роки // Статистичний довідник. - Київ, 2006. $100 \mathrm{c}$.

6. Устинова Е. И. Туберкулез глаз и сходные с ним заболевания. - Санкт- Петербург, 2002. - 275 с.

7. Фещенко Ю. І., Мельник В. М. Сучасні методи діагностики, лікування і профілактики туберкульозу // К.:Здоров'я, 2002. - С.70-107.

8. Шилова М. В., Хрулева Т. С. Проблемы туберкулеза и болезней легких // Москва. - 2005. - № 2. C. $37-40$.

9. Bach J. F. // Engl.J. Med., 2002: 347 (12). - P.911 -920

10. Schoch О. ВИЧ-ассоциированный туберкулез на примере африканских стран.// Schweizershe Medizinische Wochenscrift. - 1997. — № 29-30 O. P.1223-1227.

Поступила 17.11.2010 Рецензент канд. мед. наук Н. И. Нарицина

\title{
COMBINED APPLICATION OF ELECTROPHORESIS WITH FLOXAL AND INDOCOLLIR IN TREAT- MENT OF UVEITIS OF TUBERCULOUS ETIOLOGY
}

\section{Konovalova N. V. \\ Odessa, Ukraine}

The paper analyses the results of treatment of 125 patients with uveitis of tuberculous etiology. All patients received a nonsteroid anti-inflammatory drug Indocollir and antibacterial drug Floxal a gainst the background of complex specific antituberculosis therapy. The method of combined transorbital and endonasal electrophoresis proved to be the most effective. The pathogenetic effect of the method was directed at rapid anti-inflammatory effect and possibility to avoid complications.

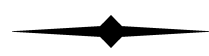

УДК 617.735-002-02:616.379-008.64-085

\section{ОПЫТ ПРИМЕНЕНИЯ РЕТИНАЛАМИНА В ЛЕЧЕНИИ ДИАБЕТИЧЕСКОЙ РЕТИНОПАТИИ}

\author{
В. В. Нероев, д-р медицинских наук, профессор, М. В. Рябина \\ ФГУ «Московский НИИ глазных болезней им. Гельмгольца Росздрава», Москва, Россия
}

Введение. Диабетическая ретинопатия (ДР) является одним из наиболее грозных осложнений сахарного диабета (СД), часто приводит к развитию слепоты и слабовидения, в том числе у лиц молодого и трудоспособного возраста. Интенсивные научные поиски последних лет направлены на понимание различных звеньев сложного и многообразного патогенеза ДР. Одним из факторов развития и прогрессирования заболевания является нарушение регуляции переноса информационных молекул между клетками. Следовательно, усиление синтеза регуляторных пептидов в самом организме или введение их извне путем применения лекарственных средств на основе пептидных препаратов (цитомединов) приводит к снижению интенсивно- сти патологического процесса, способствует восстановлению и сохранению регуляторных механизмов межклеточного взаимодействия $[1,3,5]$. Таким образом, патогенетическая обоснованность биорегулирующей терапии позволила ей получить широкое распространение в офтальмологии, в частности, при лечении пациентов с ДР.

Цель: изучение эффективности применения препарата ретиналамин в лечении пациентов с ДР на основании комплекса клинико-функциональных методов исследования.

МАТЕРИАЛ И МЕТОДЫ. В работе представлены результаты лечения ретиналамином 97 пациентов (194 гла-

(C) В. В. Нероев, М. В. Рябина, 2011 
за) с препролиферативной и пролиферативной ДР (34 мужчины и 63 женщины) в возрасте от 21 до 78 лет (средний возраст 57,3 $\pm 15,9$ лет). Среди обследуемых СД 1 типа диагностирован у 31 человека, а СД 2 типа - у 66. Средняя длительность СД составила 15,9+6,7 лет.

В работе помимо стандартного офтальмологического обследования проводились электроретинографические исследования, цветная фотография и флюоресцентная ангиография глазного дна, оптическая когерентная томография. Всем пациентам ретиналамин вводили внутримышечно в дозе 5 мг и парабульбарно по 2,5 мг в течение 10 дней. Основанием для указанного курса послужили результаты предварительных исследований, показавших более высокую эффективность данного способа комбинированного применения препарата.

РЕЗУЛЬТАТЫ И ИХ ОБСУЖДЕНИЕ. На фоне лечения ретиналамином у пациентов с ДР

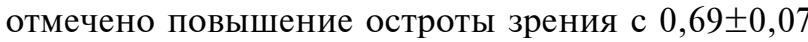
до $0,78 \pm 0,05$. Острота зрения повысилась на $0,05-$ 0,2 у $73 \%$ пациентов. Полученные результаты в большинстве случаев сохранялись в течение 5-10 месяцев.
Для объективной оценки функциональной активности сетчатки проводились электроретинографические исследования, включающие регистрацию ганц-фельд ЭРГ, ритмической и макулярной ЭРГ, определение глиального индекса (отношение амплитуды В-волны ГФ-ЭРГ к амплитуде РЭРГ на 12 Гц).

В результате лечения наблюдалось некоторое увеличение амплитуд электроретинограммы (табл. 1). Наиболее значимая положительная динамика отмечена по показателям МЭРГ и ритмической ЭРГ на частоту 32 и 40 Гц, что свидетельствует о большей чувствительности колбочковой системы сетчатки на проводимое лечение. Амплитуда А-волны, В-волны ГФ-ЭРГ и ритмическая ЭРГ на 12 Гц повышались незначительно. На фоне лечения ретиналамином отмечалось снижение исходно повышенного глиального индекса Кг с 10,3 до 9,5 ед, что свидетельствует о благоприятном влиянии препарата на глионейрональные взаимодействия и улучшении трофических процессов в сетчатке.

Таблица 1

Амплитуда биопотенциалов сетчатки у пациентов сДР до и после лечения ретиналамином (мкВ, М $\pm \mathrm{m})$

\begin{tabular}{|c|c|c|c|c|c|c|c|}
\hline & \multicolumn{2}{|c|}{ ГФ-ЭРГ } & \multicolumn{3}{|c|}{ Ритмическая ЭРГ } & \multirow{2}{*}{ МЭРГ } & \multirow{2}{*}{$\mathbf{K} \mathbf{r}$} \\
\hline & А-волна & В-волна & $12 \Gamma_{ц}$ & 32 Гц & 40 Гц & & \\
\hline До лечения & $303 \pm 3,2$ & $137,8 \pm 10,1$ & $13,3 \pm 11$ & $41 \pm 0,4$ & $23 \pm 0,3$ & $13,4 \pm 0,9$ & 10,3 \\
\hline $\begin{array}{l}\text { Амплитуда ЭРГ до лече- } \\
\text { ния в \% от нормы }\end{array}$ & $22 \%$ & $71 \%$ & $29 \%$ & $35 \%$ & $33 \%$ & $72 \%$ & $121 \%$ \\
\hline После лечения & $31,0 \pm 3,3$ & $142,8 \pm 10,3$ & $14,0 \pm 1,4$ & $4,6 \pm 0,5$ & $2,65 \pm 0,2$ & $14,4 \pm 1,0$ & 9,5 \\
\hline $\begin{array}{l}\text { Динамика амплитуды } \\
\text { ЭРГ в \% }\end{array}$ & $3 \%$ & $4 \%$ & $5 \%$ & $12 \%$ & $15 \%$ & $7,5 \%$ & $9 \%$ \\
\hline
\end{tabular}

Сравнительный анализ ангиографической картины глазного дна до и после лечения проведен у 33 пациентов (66 глаз). На фоне терапии ретиналамином отмечалось уменьшение диффузии красителя из сосудистых аномалий (микроаневризм, ИРМА), что свидетельствовало о положительном влиянии препарата на состояние внутреннего гематоретинального барьера. Полученные наблюдения согласуются с данными литературы о выраженном протективном эффекте ретиналамина в отношении сосудистого эндотелия [2,3].

Клиническими доказательствами уменьшения проницаемости сосудистой стенки на фоне приема препарата являлись частичная резорбция липидных экссудатов, уменьшение ретинального отека и количества ретинальных геморрагий. Последние факты находят поддержку в опубликованных данных о способности ретиналамина улучшать функциональное взаимодействие пигментного эпителия и наружных сегментов фоторецепторов, усиливать активность ретинальных макрофагов [3, 4, 5].

Для подтверждения положительного влияния ретиналамина на состояние внутреннего (эндотелиальные клетки, перициты) и наружного (пигментный эпителий) гематоретинального барьеров отдельно были проанализированы результаты лечения 22 пациента (27 глаз) с диффузным и фокальным макулярным отеком (МО) диабетического происхождения.

В качестве контрольного исследования для объективной количественной оценки МО проведена оптическая когерентная томография (OKT).

На фоне инъекций ретиналамина у пациентов с МО и ДР наблюдалось уменьшение толщины сетчатки, однако разница показателей до и после лечения не была достоверной (табл. 2). Выявленные положительные тенденции уменьшения МО свидетельствовали об эффективности препарата и косвенно подтвердили суждение о благотворном влиянии ретиналамина на наружный и внутренний гематоретинальные барьеры.

Таблица 2

Динамика средних значений толщины сетчатки в центре макулы до и после лечения ретиналамином (мкм)

\begin{tabular}{|c|c|c|c|c|c|}
\hline & $\begin{array}{c}\text { До лече- } \\
\text { ния }\end{array}$ & $\begin{array}{c}\text { После } \\
\text { лечения }\end{array}$ & $\begin{array}{c}\text { Через 1 } \\
\text { месяц }\end{array}$ & $\begin{array}{c}\text { Через 2 } \\
\text { месяца }\end{array}$ & $\begin{array}{c}\text { Через } \\
\text { 3 месяца }\end{array}$ \\
\hline$(\mathrm{M} \pm \mathrm{m})$ & $451 \pm 25$ & $404 \pm 23$ & $407 \pm 21$ & $413 \pm 20$ & $419 \pm 18$ \\
\hline $\mathrm{n}$ & 27 & 27 & 27 & 27 & 27 \\
\hline
\end{tabular}


Динамическое наблюдение за эволюцией ДР после курса лечения ретиналамином в течение 6-10 месяцев выявило стабилизацию общего количества микроаневризм, ИРМА и венозных деформаций, площади ишемических зон в области заднего полюса и на периферии глазного дна у большинства пациентов. Также следует отметить сохранение тенденции к уменьшению экссудативно-геморрагической активности на глазном дне у этих больных.

Переносимость ретиналамина была хорошей. Жалоб пациенты не предъявляли, побочных эффектов отмечено не было.

\section{ВЫВОДЫ}

Выявлено положительное влияние терапии с применением ретиналамина на зрительные функции, что выражалось в повышении остроты зрения на 0,05-0,2 у $73 \%$ пациентов с ДР.

Положительное влияние ретиналамина на электрогенез сетчатки выражалось в повышении функциональной активности сетчатки у 68 \% пациентов. Наиболее значимо повышалась амплитуда макулярной ЭРГ и высокочастотной ритмической ЭРГ, что свидетельствует о преимущественном влиянии препарата на колбочковый аппарат сетчатки. Снижение исходно повышенного глиального индекса указывает на улучшение глионейрональных взаимодействий в сетчатке на фоне проводимой терапии.

Отмечено положительное влияние ретиналамина на состояние внутреннего и наружного гематоретинального барьеров. Полученные результаты флюоресцентной ангиографии глазного дна и оптической когерентной томографии подтверждают протективный эффект препарата на сосудистый эндотелий и ретинальный пигментный эпителий.

\section{СПИСОК ЛИТЕРАТУРЫ}

1. Дедов И. И., Шестакова М. В., Миленькая Т. М. Сахарный диабет: ретинопатия, нефропатия. Библиотека практикующего врача. - М: Медицина. 2001. $175 \mathrm{c}$.

2. Максимов И. Б., Нероев В. В., Алексеев В. Н., Разумовский М. Н., Трофимова С. В. Применение препарата ретиналамин в офтальмологии. Пособие для врачей. - СПб.: 2003. - 20 с.

3. Морозов В. Г., Хавинсон В. Х. Пептидные биорегуляторы (25-летний опыт экспериментального и клинического изучения). - СПб.: Наука, 1996. - 74 с.

4. Трофимова СЈJ. Применение пептидных биорегуляторов при лечении диабетической ретинопатии. Автореф. Дисс....к.м.н. - СПб., 1999. - 20 с.

5. Хавинсон В. Х., Трофимова С. В. Пептидные биорегуляторы в офтальмологии. - СПб.: 2004. - 48 с.

Получена 24.11.2010 Рецензент д-р мед. наук А. А. Путиенко 